\title{
Self-compassion as a relevant intervention target for family carers of older adults: A conceptual commentary
}

Running title: Self-compassion and family carers of older adults

Jenny Murfield ${ }^{1,2^{*}}$ Orchid iD: https://orchid.org/0000-0001-9595-4242

Wendy Moyle ${ }^{1,2}$ Orchid iD: https://orchid.org/0000-0003-3004-9019

Analise O’Donovan ${ }^{2,3}$ Orchid iD: https://orchid.org/0000-0002-0776-095

${ }^{1}$ School of Nursing \& Midwifery, Griffith University, Nathan, Queensland, Australia

${ }^{2}$ Menzies Health Institute Queensland, Griffith University, Nathan, Queensland, Australia

${ }^{3}$ School of Applied Psychology, Griffith University, Gold Coast, Queensland, Australia

Corresponding author*: Jenny Murfield, School of Nursing \& Midwifery, Menzies Health Institute Queensland, Griffith University, Health Sciences (N48), 170 Kessels Road, Nathan, Brisbane, Queensland, 4111, Australia. Email: j.murfield@griffith.edu.au

This article has been accepted for publication and undergone full peer review but has not been through the copyediting, typesetting, pagination and proofreading process which may lead to differences between this version and the Version of Record. Please cite this article as doi: $10.1002 /$ gps.5257 
Acknowledgements: This research was supported by a Griffith University Postgraduate Research Scholarship, awarded to Jenny Murfield.

Conflict of interests: The authors declared no potential conflicts of interest with respect to the research, authorship, and/or publication of this article. 


\title{
Self-compassion as a relevant intervention target for family carers of older adults: A conceptual commentary
}

\author{
KEY WORDS \\ Caring; Compassion; Family Caregiver; Mental Health
}

\section{KEY POINTS}

- Psychological interventions that seek to specifically increase levels of self-compassion could help stress management by promoting adaptive emotion regulation.

- Within the population context of family carers of older adults, there is currently limited research into self-compassion, and the potential theoretical underpinnings of self-compassion as a form of support for this group have not been explored.

- We outline a conceptual rationale for why self-compassion is an applicable intervention target for family carers of older adults, bringing together understanding and evidence from the perspectives of family caregiver stress and emotional regulation.

- Considerations for future research include additional proof-of-concept work, addressing perceptions of self-compassion, and involvement of family carers of older adults in the design and adaptation of self-compassion interventions. 


\section{INTRODUCTION}

Caring for an older family member can be a challenging and stressful experience, and there is a need to better support family carers in their role. ${ }^{1}$ Drawing on a rapidly growing body of research conducted with various population groups, ${ }^{2}$ there is reason to suggest that psychological interventions that target self-compassion could be particularly relevant in supporting family carers of older adults. Yet, research exploring self-compassion within this population is currently very limited, ${ }^{3}$ and the potential theoretical underpinnings of self-compassion as an intervention and/or form of support for this group have not been explored. Within this paper, we outline for the first time, a conceptual rationale for why self-compassion is an applicable intervention target for family carers of older adults. In doing so, we situate the discussion within current understanding and evidence about family caregiving stress, and use an emotion regulation framework to explore the mechanism of change though which self-compassion may positively influence carer health outcomes. This conceptual commentary is intended to encourage and guide research in a new and rapidly developing area and, to this end, we provide a series of considerations for future research to extend current understanding.

Within this paper, our conceptual discussion is organised into eight main sections. First, we begin by describing family caregiving within the context of an aging population, then move on to describe transactional models of family caregiving stress, and outline psychological interventions used with family carers of older adults. We then introduce, define, and describe the concept of self-compassion, which is followed with a review of the empirical literature on selfcompassion and wellbeing, and the role that emotional regulation is proposed to play. We then 
discuss and review evidence for the relevance of self-compassion as an intervention target for family carers of older adults, and end the paper by presenting suggestions for future research to advance knowledge.

\section{FAMILY CARING IN AN AGING POPULATION}

The world's population is rapidly aging and, with it, societies are experiencing demographic shifts unlike anything seen before. ${ }^{4}$ In 2015 , around $12 \%$ of the global population was aged 60 years or older. ${ }^{4}$ However, over the next 45 -year period alone, these rates are expected to nearly double, and older adults will account for over one-fifth (22\%) of the global population by $2050 .^{4}$ These dramatic shifts will impact societies in a number of ways, and this will include changes in the dynamics and provision of future long-term care. ${ }^{5}$ Currently, the majority of older adults with care dependent needs remain living in the community, although rates vary between countries, and receive a significant amount of care and support from an informal, unpaid network of family

members, friends, and neighbours. ${ }^{5}$ Women aged 30-64 years are most likely to provide the bulk of this care, usually for a parent or spouse, and engage in a range of tasks to support emotional needs, and both basic and instrumental activities of daily living. ${ }^{5,6}$ This can include activities such as assistance with bathing, feeding, dressing, as well as management of finances, communication, and medication. From a purely economic stand-point, the value of this informal care is immense, and it is estimated that to replace it with formal paid care services would cost billions, for example USD $\$ 221$ billion in the US, AUD\$60 billion in Australia, and GBP£132 billion in the UK. ${ }^{7-9}$ 
Living within the community is typically preferred over admission to a residential or nursing facility by older adults and their families, ${ }^{10}$ and, indeed, community living can bring many positive rewards for both members of the care dyad. ${ }^{11}$ However, an extensive body of research shows that caring for an older family member can also be a stressful and challenging experience. ${ }^{12}$ Across the extant literature, the prevalence of psychological distress (e.g., depression, anxiety, stress etc.), burden, loneliness, isolation, chronic conditions (e.g., cardiovascular disease, diabetes, osteoporosis etc.), impaired immunity and altered stress hormones, and disability is consistently higher in carers than non-caregivers; ${ }^{13-15}$ and this difference is most pronounced for carers of people with dementia. ${ }^{16}$ Alongside this there are often adverse financial consequences, with a reduced ability to participate in the paid workforce placing many carers under day-to-day economic strain and inhibiting longer-term financial planning, such as saving for retirement. ${ }^{6,12,13}$ The potential implications of these effects are farreaching for some carers, as poor carer mental health is a known risk factor for suicidal ideation in family carers of people with dementia, ${ }^{17}$ increased neglect and abuse of older adults, ${ }^{18}$ and increased mortality of people with neurodegenerative diseases. ${ }^{19}$ Importantly, however, it is also well-known that not all family carers are negatively affected as a result of their role, and that individuals with similar caregiving profiles can often be differentially affected by the demands placed on them. ${ }^{20}$ The need to better understand how and why such variability occurs has driven much research over the last two decades, and a number of conceptual frameworks for caregiver stress and coping have been developed as a result. ${ }^{20,21}$ Of the various frameworks available, transactional models of stress have been particularly influential, and the best known and applied 
models, the Transactional Model of Stress and Coping ${ }^{22}$ and the Stress Process Model, ${ }^{23}$ have underpinned much of the research effort.

\section{TRANSACTIONAL MODELS OF FAMILY CAREGIVING STRESS}

Transactional models of stress propose that caregiver stress is a complex and multifaceted process between the person and their environment, and that the effect of stressors on the carer is dependent on several mediating variables, most typically including social support and coping

strategies. $^{22,23}$ Across transactional models, four domains are broadly identified as being key in the stress process, and these help explain why carers vary in their experience: 1) background and contextual variables, which include characteristics of the carer, such as sex, age, and socioeconomics; 2) type of stressor, including objective/primary stressors, such as the care needs of the older adult, as well as subjective/secondary stressors, such as the effects of objective stressors on areas of life related to family, economy, and work, as well as the person's cognitive appraisal of objective/primary stressors; 3) mediating variables, such as social support and coping strategies; and 4) outcomes, which include the effects on the person's psychological and physical health. Within these models, the stress process is considered fluid and, because the various domains are understood to be temporal in nature and have a non-linear relationship to each other (often feeding backwards and forwards), this explains why the same stressor, experienced at various time-points, can have a different effect on the family carer. In the main, transactional models of caregiving assume a stress-coping focus, seeing the physical needs of the care recipient and the practical demands this poses for the caregiver as particular stressors that 
impact coping and, in turn, the health outcomes of the carer. However, more recently, a number of models of caregiving have built-on and extended the conceptual focus on stress-coping to better understand the complex interplay of the domains. Of these, this includes the sociocultural stress-process model, which highlights cultural and ethnicity-based values as particularly influential in the stress process by varying the impact of the domains on the caregiver. ${ }^{24}$ Alongside this, there is also the suffering-compassion model, which proposes that care recipient suffering is as an independent stressor in the caregiving process, and one that is mediated by compassion. ${ }^{25}$ In the context of this paper, it is important to note that the suffering-compassion model of caregiving understands and includes compassion only as it relate to compassion for the care recipient. It does not explore the role that the other facets of compassion, including selfcompassion (which will be described in proceeding sections), may play in the caregiving stress process.

Drawing on transactional models of caregiving stress, considerable research effort has focused on developing family carer interventions in order to mitigate the negative effects of stressors on carer health outcomes. Chiefly, these interventions have focused on either a reduction in the objective stress (i.e., respite care services), or the modification of mediating variables (i.e., psychoeducation and support groups) to improve carer outcomes. ${ }^{26}$ These efforts have informed clinical recommendations, ${ }^{27}$ and have directly translated into practice internationally, with a host of support services currently available to carers. Yet, despite these efforts, data consistently shows that services remain under-utilised, ${ }^{28,29}$ and many carers continue to report unmet support needs that lead to considerable stress. ${ }^{28-30}$ In research exploring how to 
better support carers in their role, greater emotional support to aid stress-management and coping, especially from professionals, has emerged as an important area of need. ${ }^{30,31}$ Such findings suggest that approaches focused on cognitive appraisal and adaptive coping may be an optimum way of supporting family carers of older adults by directly meeting a self-identified need. For this reason, psychological interventions appear a warranted focus in family carer support service research and development.

\section{PSYCHOLOGICAL INTERVENTIONS FOR FAMILY CARERS OF OLDER}

\section{ADULTS}

Over the last few decades, there has been a rapid increase in the number of psychological programs, therapies, and interventions used to help improve the emotional wellbeing of family carers of older adult populations. Broadly, this has included four main intervention types: psychoeducation-skill building, counseling/ psychotherapy, multicomponent interventions, and approaches based on the principles of mindfulness, acceptance, and compassion..$^{32}$ Of these interventions, Cognitive Behavioural Therapy (CBT) has been most consistently evidenced in the family caregiving literature, and moderate to large effects have been shown for carers on the outcomes of burden, anxiety, and depression. ${ }^{32}$ More recently, however, there is also emerging evidence for the potential efficacy of newer, so-called 'third-wave' approaches, such as Acceptance and Commitment Therapy, ${ }^{33}$ Dialectical Behaviour Therapy, ${ }^{34}$ Mindfulness-Based Stress Reduction, ${ }^{35}$ and Compassion-Focused Therapy. ${ }^{36}$ Evolving from a CBT framework, these transdiagnostic approaches seek to explore how a person associates and responds to their 
symptoms and experiences in order to address thought patterns. ${ }^{37}$ Mindfulness approaches typically achieve this through focusing on the non-judgmental awareness and acceptance of present-moment experiences; acceptance-based approaches typically focus on the acceptance of thoughts and feelings using an action-orientated approach; and compassion-based approaches focus on the cultivation of compassionate feelings for self and others. Findings from reviews and meta-analyses demonstrate potential effectiveness of these approaches in improving symptoms of depression, burden, stress, and anxiety for older family carer populations, most particularly carers of people with dementia. ${ }^{38}$ However, in terms of self-compassion interventions specifically, which is the focus of this paper, there is scant evidence available and it appears to be to be a largely neglected research area within family carers of older adults. Nevertheless, as we will describe in the remainder of this article, there are a number of theoretical indicators to suggest self-compassion could be a potentially relevant and alternate approach to improving the emotional health of this population and is, therefore, a research area deserved of further attention. $^{3}$

\section{SELF-COMPASSION}

The concept of self-compassion originates from the ancient spiritual teachings of Buddhism, yet it's emergence within the scientific literature is far more recent, with it first becoming a focus of interest around two decades ago. In terms of definition, self-compassion is closely related to the more general definition of compassion, which is typically understood as the recognition of suffering, both in self and others, coupled with a commitment to try to alleviate and prevent 
it. $^{39,40}$ Self-compassion is considered a healthy form of self-to-self relating and, in essence, is about treating oneself with the same compassion we would give to another. In the earliest work in the area, self-compassion was conceptualised from a Theravada (mindfulness) Buddhism perspective, and was defined as the predominance of three positive attitudinal dimensions over their negatively-paired opposites: 1) self-kindness over self-judgement (i.e., being non-critical towards the self during times of suffering); 2) common humanity over isolation (i.e., recognising everyone experiences hardships); and 3) mindfulness over over-identification (i.e., a calm and balanced awareness of negative thoughts and experiences). ${ }^{41}$ Building on this definition, an 8week workshop program, Mindful Self-Compassion (MSC), was developed to cultivate selfcompassion in both general and clinical populations. ${ }^{42,43}$ Alongside this, the Self-Compassion Scale (SCS) and its short-form variant (SCS-SF) were constructed to operationally measure trait levels of self-compassion. ${ }^{44,45}$ To date, the SCS remains the most commonly used measure of self-compassion; however, its validity has come under increasing scrutiny, with particular concerns raised about the use of a global score (for criticism and rebuttals, please see Muris et $\mathrm{al}^{46}$ and Neff et $\mathrm{al}^{47}$ ).

In another complementary yet alternate model, self-compassion is conceptualised from an evolutionary, neuroscience, and social psychology perspective. ${ }^{48}$ Drawing on social mentality theory, ${ }^{49}$ this approach sees self-compassion as part of a three-way interactive flow involving compassionate self-to-self, self-to-other, and other-to-self relating. Three basic affect-regulation systems are highlighted within the approach, and the co-regulation of these are linked to attachment patterns and experiences during early life: 1) threat and self-protection system; 2) 
drive-reward system; and 3) soothing-affiliation system. It is theorised that self-compassion helps facilitate more adaptive physiological emotion regulation by activating the affiliative processing system associated with secure attachment and caregiving (i.e., release of caregiving hormones such as oxytocin and decreased heart rate), while deactivating the threat system associated with insecure attachment (i.e., the limbic system). ${ }^{40}$ Compassion Focused Therapy (CFT) was developed from this model, ${ }^{49}$ first as a form of psychotherapy for people experiencing high levels of shame and self-criticism, but has since been used with various populations to improve a range of psychological health outcomes. ${ }^{50}$ More recently, an 8-week group-based approach derived from the CFT model, Compassionate Mind Training (CMT), ${ }^{51}$ has also been developed. Alongside this, the three-way flow of compassion has been operationalised for measurement with the Compassionate Engagement and Actions Scales (CEAS). ${ }^{52}$

Within both academic and general understanding, self-compassion is often confused with a number of different concepts, most often including self-pity and self-esteem. While a discussion of all the multifaceted and complex differences is beyond the scope of this paper, it is important to provide a cursive summary of the ways in which self-compassion is distinct to aid definitional understanding (for a more detailed discussion, please see Barnard et $\mathrm{al}^{53}$ ). First, in terms of self-compassion versus self-pity, a key point of difference is the focus on nonjudgmental awareness of suffering and the recognition that it is not unique to oneself. Whereas self-pity is associated with feelings of disconnection from others and the self-focused immersion on individual suffering, self-compassion sees the deliberate and balanced awareness of suffering as part of a common humanity. ${ }^{41}$ Further, within self-compassion, there is the motivation to try to 
alleviate or prevent the suffering, which is a component absent within self-pity and, as a result, can see an individual becoming stuck in their negative affective state with no commitment to move beyond. Regarding the difference between self-compassion and self-esteem, the main distinctions lie with self-to-self relating and the element of self-kindness. ${ }^{54}$ In self-compassion, an individual extends care and kindness to oneself, which facilitates acceptance and self-worth, and avoids self-judgment during times of suffering. In contrast, self-esteem is contingent on the positive evaluation of qualities and abilities of the self, requiring comparison and judgment against others (and which research has shown can be positively associated with narcissism). ${ }^{39,41,54}$ During difficult times, such evaluations can lead to critical self-talk and poor self-to-self relating, which is the exact opposite of self-compassion.

\section{SELF-COMPASSION AND WELLBEING}

Within a rapidly growing body of research conducted with various clinical, sub-clinical, and general populations, self-compassion has emerged as a potentially healthy way of managing stress. ${ }^{2,53}$ Whereas traditionally understood as a dispositional trait, self-compassion has also been shown to be a modifiable skill that can be taught and developed, ${ }^{43}$ and which can activate positive emotions $^{55}$ and provide adaptive protection against the development of psychopathology. ${ }^{56}$ Interventional research conducted across the lifespan has shown selfcompassion to be positively associated with psychological well-being, ${ }^{56,57}$ and negatively

associated with mental ill health. ${ }^{53,57,58}$ Specifically, targeted self-compassion interventions have been found particularly effective in the treatment of eating difficulties and rumination (large 
effects), as well as having positive effects on depression, stress, anxiety, self-criticism, selfcompassion, mindfulness, positive and negative affect, and life satisfaction (moderate to small effects). ${ }^{2}$ Self-compassion has also been implicated in the aetiology of suicidality, with higher

levels of self-compassion associated with lower levels of self-harm and suicidal ideation. ${ }^{59}$ More recently, studies have also begun to explore the potential of self-compassion in the stressmanagement process of various formal healthcare professionals. In these early studies, greater self-compassion has been linked to reduced burnout and fatigue in both hospital and community nurses and student midwives. ${ }^{60-63}$ Further, interventional research specifically targeting selfcompassion with nurses has also shown promising effects, with increases in compassion and resilience, and decreases in secondary trauma and burnout demonstrated after an 8-week pilot MSC program. ${ }^{64}$ Given these promising findings, and the ever-growing number of studies, researchers have begun to explore the mechanism of change through which self-compassion operates in order to better understand its positive impact on health outcomes. Although still an emerging area, early research suggests that self-compassion positively impacts psychological health through facilitating adaptive emotion regulation. ${ }^{65}$

\section{SELF-COMPASSION AND EMOTION REGULATION}

Emotion regulation refers to a range of cognitive, behavioural, and physiological processes, both automatic and deliberate, that collectively interact to influence how a person experiences the intensity, duration, and expression of an emotion. ${ }^{66}$ It is well established that the way in which emotions are regulated varies between individuals, and a number of taxonomies have been 
proposed that explore differing affective profiles and the use of specific adaptive and maladaptive emotion regulation strategies. ${ }^{66,67}$ From this research, deficits in emotion regulation have been associated with psychopathology ${ }^{68}$ Specifically, individuals with poorer mental health have been found to more commonly employ maladaptive strategies, such as rumination, suppression, and avoidance. ${ }^{66,67}$ However, individuals with healthy forms of emotion regulation appear to use more adaptive strategies, and emotional acceptance, tolerance, and cognitive reappraisal of negative emotions have been found particularly important for good mental health. ${ }^{67}$ Within self-compassion research, there is growing evidence that self-compassion facilitates the use of adaptive emotion regulation strategies, particularly in terms of positive cognitive reframing, ${ }^{69}$ and greater emotional awareness, appraisal, and acceptance. ${ }^{70}$ Within the first meta-analysis conducted in the area, emotion regulation was identified as the mediating factor between self-compassion and mental health in community and clinical populations with various mental health symptoms. ${ }^{65}$ Specifically, increased tolerance of negative emotions was identified as a key way in which self-compassion interventions facilitated positive mental health outcomes, and it was proposed that individuals who avoid emotional experience may benefit from self-compassion interventions in particular. ${ }^{65}$ Alongside this, there is also growing evidence that self-compassion interventions facilitate adaptive emotion regulation through moderating physiological stress responses. For example, in a study involving healthy adults, ${ }^{71}$ two brief selfcompassion conditions significantly increased parasympathetic nervous system activation through increased vagally-mediated heart rate variability( vmHRV), and reduced arousal via reduced heart rate and skin conductance, when compared to three control conditions (negative, 
neutral, and positive valence). Further, within another healthy sample, ${ }^{72}$ increased immune response (measured via salivary immunoglobulin), and reduced stress hormones (measured via salivary cortisol), were found after an 8-week mindfulness and self-compassion intervention. When taken together, these findings suggest that self-compassion could be a useful intervention target for populations under stress by promoting adaptive emotion regulation, both psychological and physiological. ${ }^{65}$ As such, self-compassion based interventions may be of particular benefit to family carers of older adults whom, as outlined in the earlier part of this paper, are known to be under considerable stress as a result of their caregiving role. 


\section{SELF-COMPASSION AS A RELEVANT INTERVENTION TARGET FOR FAMILY CARERS OF OLDER ADULTS}

Research exploring the relevance of self-compassion as an intervention target for family carers of older adults is newly emerging (appearing first within the literature from 2013) and, as expected in areas of research infancy, studies are currently limited in number and scope. ${ }^{3}$ Nevertheless, from the early work undertaken, there is preliminary evidence to suggest the potential for self-compassion interventions to help modify family carer stress by providing protective emotional adaption. In cross-sectional research conducted with family carers of people with dementia, higher levels of self-compassion were associated with greater use of emotionfocused coping strategies and lower levels of burden. ${ }^{73}$ Similarly, in partner caregivers of people with neurological conditions (i.e., spinal cord injury, dementia), levels of self-compassion and quality of life emerged as significant predictors of depression (shared variance of $48.8 \%$ ). ${ }^{74}$ Although no intervention study has yet to specifically target and measure self-compassion within this carer population, a 6-week pilot study of CFT has been conducted with dyads of communitydwelling people with dementia and their family carers in order to promote compassionate relating. Although statistically underpowered $(\mathrm{n}=34)$, and not measuring self-compassion as an outcome, this study showed a clinically significant reduction in carers' respiratory rate postintervention (suggestive of improved psychological wellbeing), and showed trends towards reduced levels of self-reported anxiety and depression. ${ }^{75}$ The intervention was also positively evaluated by carers and was well tolerated, as evidenced by a low rate of attrition (6\%). These nascent findings provide preliminarily support for the rationale that interventions that target self- 
compassion, as a mediating variable in the stress process, may help family carers of older adults in their role by enabling more adaptive emotion regulation. In other words, cultivating selfcompassion in carers can lead to greater use of more helpful ways of coping, particularly cognitive appraisal and acceptance of a stressor, which can help lead to more positive outcomes in terms of their psychological and physical health. More research is now needed to advance understanding in this area further and, to help encourage and inform the development of such endeavors, a series of considerations for future research are provided in the following section.

\section{CONSIDERATIONS FOR FUTURE RESEARCH}

\subsection{Exploring proof-of-concept further}

Given the importance of conducting initial exploratory, proof-of-concept work in an emerging area of interest, it is necessary to further understand associations between self-compassion and known psychological and physical health outcomes for this population. Additional crosssectional survey work is needed to help establish more definitively how self-compassion relates to outcomes in the caregiving stress process, as well as explore whether self-compassion's mechanism of change is through the mediating effect of emotional regulation. In doing so, surveys should also aim for an international scope to enable the potential influence of important socio-cultural aspects to be evaluated. ${ }^{24}$ Similarly, contextual and background factors about both the carer and older adult care recipient should also be considered in the evaluation, such as carers' sex, relationship, and type of chronic condition, as these are also important in the stress process. ${ }^{22,23}$ In addition, building on the suffering-compassion model of caregiving, ${ }^{25}$ which is 
focused on compassion for the care recipient only, consideration should be given to measuring all three aspects of compassion (for self, for others, and from others) in order to fully explore the role that compassion might play in the stress process, and how the three aspects relate to each other. Finally, the reliability and validity of scales used to measure levels of self-compassion should be fully explored in all work. Within the two cross-sectional surveys conducted to date, both used the SCS-SF; however, the reported reliability ranged between studies, from poor $(a=0.55)^{73}$ to excellent $(a=0.90) \cdot{ }^{74}$ As such, future research should seek to establish and confirm the reliability of the SCS-SF for use family carers of older adults, and also consider exploring use of the SCS and the CEAS, with the psychometric metrics of each scale assessed and reported.

\subsection{Addressing perceptions of self-compassion}

As this paper has outlined, the cultivation of self-compassion affords many positive benefits for health and wellbeing by facilitating an adaptive way of managing emotions. However, within both research and clinical practice, it is also recognised that the development of self-compassion is challenging and that, when doing so, individuals can come up against a number of personal fears, blocks, and resistances. ${ }^{76}$ It is very common when first practicing self-compassion for individuals to experience a phenomenon known as 'backdraft', which sees unpleasant feelings and emotions brought to the fore, as old relational hurts and memories are recalled. ${ }^{77}$ This emotional activation can be particularly challenging for individuals who are highly self-critical or have experienced abusive or low affection childhoods, as offering oneself compassion can 
trigger feelings associated with low self-worth and unresolved grief. ${ }^{36}$ Alongside this, there is also evidence that various metacognitions are associated with self-compassion: many individuals are fearful of positive emotions, believing that it will make them weak, that they are undeserving, or that, by dropping their guard, something bad will happen. ${ }^{36}$ Although research into fears and perceptions of self-compassion amongst family carers of older adults has yet to be undertaken, it is likely that many fears, blocks, and resistances will be prevalent, and particularly so given evidence that carers often experience feelings of guilt and negative self-appraisal. ${ }^{78}$ As such, it is important that psychological interventions that specifically target self-compassion also target perceptions and fears of self-compassion during the process. Many of the current compassionfocused interventions, including CFT, CMT, MSC, directly address fears of compassion. However, to aid future intervention development, more research is needed to explore the fears and perceptions of self-compassion as they relate to this population specifically. ${ }^{76}$

\subsection{Developing and refining interventions through family carer involvement}

There are currently six empirically supported compassion interventions reported in the literature that focus on the cultivation of compassion for the self and others ${ }^{79}$ including, most notably, MSC, CFT, and CMT. However, these interventions have not been tested for use with family carers of older adults and, to-date, only one small-scale dyadic study of CFT has been undertaken with people with dementia and their family carers. ${ }^{75}$ As such, these interventions should be tested, initially for feasibility then efficacy, for use with this population group. In doing so, there is also scope for these existing interventions to be developed and tailored further, 
and person-based approaches, ${ }^{80}$ which are grounded in the lived experience of family carers of older adults and use the principles of co-design, are encouraged. The importance of including health service users throughout the research process is internationally recognised, and data increasingly shows that doing so leads to greater effectiveness and better translation of findings into practice. ${ }^{81}$ Therefore, consideration should be given to including family carers, practitioners, and researchers in the processes of development and refinement of self-compassion interventions to ensure real-world relevance, acceptability, and feasibility from the perspective of those the intervention is intended for.

\section{CONCLUDING COMMENTS}

Within this commentary, we have sought to conceptually outline, for the first time, why selfcompassion is an applicable intervention target for family carers of older adults by bringing together understanding and supporting evidence from the perspective of family caregiver stress theory and emotional regulation. Building on our rationale, more research is now needed to empirically explore the applicability, efficacy, and effectiveness of self-compassion as an intervention target for this population. 


\section{REFERENCES}

1. Qualls SH. Caregiving families within the long-term services and support system for older adults. Am Psychol. 2016;71(4):283-293.

2. Ferrari M, Hunt C, Harrysunker A, Abbott MJ, Beath AP, Einstein DA. Self-compassion interventions and psychosocial outcomes: a meta-analysis of RCTs. Mindfulness. 2019;10(8):1455-1473.

3. Murfield J, Moyle W, Jones C, O’Donovan A. Self-compassion, health outcomes, and family carers of older adults: an integrative review. Clin Gerontol. January 2019:1-14.

4. World Health Organization. Ageing and health. 2018; https://www.who.int/newsroom/fact-sheets/detail/ageing-and-health. Accessed June 17, 2019.

5. World Health Organization. World report on ageing and health. 2015; http://apps.who.int/iris/bitstream/handle/10665/186463/9789240694811_eng.pdf?sequen ce=1. Accessed August 5, 2019.

6. Embracing Carers. 2017 carers report: Embracing the critical role of caregivers around the world. White paper and action plan. 2017; https://www.embracingcarers.com/content/dam/web/healthcare/corporate/embracingcarers/media/infographics/us/Merck KGaA Embracing Carers_White Paper Flattened.pdf. Accessed August 5, 2019.

7. Carers Australia. The economic value of informal care in Australia in 2015. 2015; https://www.carersaustralia.com.au/storage/Access Economics Report.pdf. Accessed August 26, 2019. 
8. Chari AV, Engberg J, Ray KN, Mehrotra A. The opportunity costs of informal elder-care in the United States: new estimates from the American Time Use Survey. Health Serv Res. 2015;50(3):871-882.

9. $\quad$ Buckner L, Yeandle S. Valuing carers 2015. 2015; https://www.sheffield.ac.uk/polopoly_fs/1.546409!/file/Valuing-Carers-2015.pdf. Accessed August 26, 2019.

10. Stones D, Gullifer J. 'At home it's just so much easier to be yourself’: older adults' perceptions of ageing in place. Aging Soc. 2016;36(3):449-481.

11. Lloyd J, Patterson T, Muers J. The positive aspects of caregiving in dementia: a critical review of the qualitative literature. Dementia. 2014;15(6):1534-1561.

12. Adelman RD, Tmanova LL, Delgado D, Dion S, Lachs MS. Caregiver burden: a clinical review. JAMA. 2014;311(10):1052-1060.

13. Carers UK. State of Caring: A snapshot of unpaid care in the UK. 2019; http://www.carersuk.org/stateofcaring-report. Accessed August 5, 2019.

14. Stacey AF, Gill TK, Price K, Taylor AW. Differences in risk factors and chronic conditions between informal (family) carers and non-carers using a population-based cross-sectional survey in South Australia. BMJ Open. 2018;8(7):e020173.

15. Whittaker AC, Gallagher S. Caregiving alters immunity and stress hormones: a review of recent research. Curr Opin Behav Sci. 2019;28(Aug):93-97.

16. Collins RN, Kishita N. Prevalence of depression and burden among informal care-givers of people with dementia: a meta-analysis. Ageing Soc. June 2019:1-38. 
17. Joling KJ, O'Dwyer ST, Hertogh CMPM, van Hout HPJ. The occurrence and persistence of thoughts of suicide, self-harm and death in family caregivers of people with dementia: a longitudinal data analysis over 2 years. Int J Geriatr Psychiatry. 2018;33(2):263-270.

18. Kohn R, Verhoek-Oftedahl W. Caregiving and elder abuse. Med Health R I. 2011;94(2):47-49.

19. Lwi SJ, Ford BQ, Casey JJ, Miller BL, Levenson RW. Poor caregiver mental health predicts mortality of patients with neurodegenerative disease. Proc Natl Acad Sci U S A. 2017;114(28):7319-7324.

20. Losada-Baltar A. Stress and Coping in Caregivers, Theories of. In: Pachana NA, ed. Encyclopedia of Geropsychology. Singapore: Springer Singapore; 2017:2268-2276.

21. Figueiredo D. Caregiving and Carer Stress. In: Pachana NA, ed. Encyclopedia of Geropsychology. Singapore: Springer Singapore; 2017:445-455.

22. Lazarus RS, Folkman S. Stress, appraisal, and coping. New York: Springer Publishing; 1984.

23. Pearlin LI, Mullan JT, Semple SJ, Skaff MM. Caregiving and the stress process: an overview of concepts and their measures. Gerontologist. 1990;30(5):583-594.

24. Knight BG, Sayegh P. Cultural values and caregiving: the updated sociocultural stress and coping model. J Gerontol B Psychol Sci Soc Sci. 2010;65b(1):5-13.

25. Schulz R, Hebert RS, Dew MA, Brown SL, Scheier MF, Beach SR, et al. Patient suffering and caregiver compassion: new opportunities for research, practice, and policy. Gerontologist. 2007;47(1):4-13. 
26. Sörensen S, Pinquart M, Duberstein P. How effective are interventions with caregivers? an updated meta-analysis. Gerontologist. 2002;42(3):356-372.

27. National Institute for Health and Care Excellence. Dementia: Assessment, management and support for people living with dementia and their carers. 2018; https://www.nice.org.uk/guidance/ng97. Accessed August 26, 2019.

28. Heath A, Carey LB, Chong S. Helping carers care: an exploratory study of factors impacting informal family carers and their use of aged care services. J Relig Health. 2018;57(3):1146-1167.

29. Stockwell-Smith G, Kellett U, Moyle W. Why carers of frail older people are not using available respite services: an Australian study. J Clin Nurs. 2010;19(13-14):2057-2064.

30. Temple JB, Dow B. The unmet support needs of carers of older Australians: prevalence and mental health. Int Psychogeriatr. 2018;30(12):1849-1860.

31. Silva AL, Teixeira HJ, Teixeira MJ, Freitas S. The needs of informal caregivers of elderly people living at home: an integrative review. Scand J Caring Sci. 2013;27(4):792803.

32. Cheng ST, Au A, Losada A, Thompson LW, Gallagher-Thompson D. Psychological interventions for dementia caregivers: what we have achieved, what we have learned. Curr Psychiatry Rep. 2019;21(7):59.

33. Hayes SC, Strosahl KD, Wilson KG. Acceptance and commitment therapy: An experiential approach to behaviour change. New York: Guilford Press; 1999. 
34. Linehan M. Skills training manual for treating borderline personality disorder. New York: Guilford Press; 1993.

35. Kabat-Zinn J. Mindfulness-based stress reduction. Constructivism in the Human Sciences. 2003;8(2):73-107.

36. Gilbert P. Compassion focused therapy: Distinctive features. New York: Routledge; 2010.

37. Hofmann SG, Sawyer AT, Fang A. The empirical status of the "new wave" of cognitive behavioral therapy. Psychiatr Clin North Am. 2010;33(3):701-710.

38. Collins RN, Kishita N. The effectiveness of mindfulness- and acceptance-based interventions for informal caregivers of people with dementia: a meta-analysis. Gerontologist. 2019;59(4):e363-e379.

39. Neff K. Self-compassion: The proven power of being kind to yourself. New York: William Morrow; 2011.

40. Gilbert P. The origins and nature of compassion focused therapy. Br J Clin Psychol. 2014;53(1):6-41.

41. Neff K. Self-compassion: An alternative conceptualization of a healthy attitude toward oneself. Self and Identity. 2003;2(2):85-101.

42. Germer CK, Neff KD. Self-compassion in clinical practice. J Clin Psychol. 2013;69(8):856-867.

43. Neff KD, Germer CK. A pilot study and randomized controlled trial of the mindful selfcompassion program. J Clin Psychol. 2013;69(1):28-44. 
44. Neff KD. The development and validation of a scale to measure self-compassion. Self and identity. 2003;2(3):223-250.

45. Raes F, Pommier E, Neff KD, Van Gucht D. Construction and factorial validation of a short form of the Self-Compassion Scale. Clin Psychol Psychother. 2011;18(3):250-255.

46. Muris P, Petrocchi N. Protection or vulnerability? A meta-analysis of the relations between the positive and negative components of self-compassion and psychopathology. Clin Psychol Psychother. 2017;24(2):373-383.

47. Neff KD, Tóth-Király I, Yarnell LM, Arimitsu K, Castilho P, Ghorbani N, et al. Examining the factor structure of the Self-Compassion Scale in 20 diverse samples: support for use of a total score and six subscale scores. Psychol Assess. 2018;31(1):27-45.

48. Gilbert P. Compassion: Conceptualisations, research and use in psychotherapy. New York: Routledge; 2005.

49. Gilbert P. Introducing compassion-focused therapy. Adv Psychiatr Treat. 2009;15(3):199-208.

50. Leaviss J, Uttley L. Psychotherapeutic benefits of compassion-focused therapy: an early systematic review. Psychol Med. 2015;45(5):927-945.

51. Irons C, Beaumont E. The compassionate mind workbook: A step-by-step guide to developing your compassionate self. UK: Little Brown Book Group; 2017.

52. Gilbert P, Catarino F, Duarte C, Matos M, Kolts R, Stubbs J, et al. The development of compassionate engagement and action scales for self and others. J Compassionate Health Care. 2017;4(1):4. 
53. Barnard LK, Curry JF. Self-compassion: conceptualizations, correlates, \& interventions. Rev Gen Psychol. 2011;15(4):289-303.

54. Neff KD, Vonk R. Self-compassion versus global self-esteem: two different ways of relating to oneself. J Pers. 2009;77(1):23-50.

55. Germer C, Barnhofer T. Mindfulness and compassion: Similaritlies and differences. In: Gilbert P, ed. Compassion: Concepts, research and applications. Oxon, UK: Routledge; 2017:69-86.

56. Zessin U, Dickhäuser O, Garbade S. The relationship between self-compassion and wellbeing: a meta-analysis. Appl Psychol Health Well Being. 2015;7(3):340-364.

57. Brown L, Huffman JC, Bryant C. Self-compassionate aging: a systematic review. Gerontologist. 2018;59(4):e311-e324.

58. MacBeth A, Gumley A. Exploring compassion: a meta-analysis of the association between self-compassion and psychopathology. Clin Psychol Rev. 2012;32(6):545-552.

59. Cleare S, Gumley A, O'Connor RC. Self-compassion, self-forgiveness, suicidal ideation, and self-harm: a systematic review. Clin Psychol Psychother. May 2019:1-20.

60. Dev V, Fernando AT, Lim AG, Consedine NS. Does self-compassion mitigate the relationship between burnout and barriers to compassion? A cross-sectional quantitative study of 799 nurses. Int J Nurs Stud. 2018;81:81-88.

61. Durkin M, Beaumont E, Hollins Martin CJ, Carson J. A pilot study exploring the relationship between self-compassion, self-judgement, self-kindness, compassion, 
professional quality of life and wellbeing among UK community nurses. Nurse Educ Today. 2016;46:109-114.

62. Vaillancourt ES, Wasylkiw L. The intermediary role of burnout in the relationship between self-compassion and job satisfaction among nurses. Can J Nurs Res. April 2019:844562119846274.

63. Beaumont E, Durkin M, Hollins Martin CJ, Carson J. Compassion for others, selfcompassion, quality of life and mental well-being measures and their association with compassion fatigue and burnout in student midwives: a quantitative survey. Midwifery. 2016;34:239-244.

64. Delaney MC. Caring for the caregivers: evaluation of the effect of an eight-week pilot mindful self-compassion (MSC) training program on nurses' compassion fatigue and resilience. PLoS One. 2018;13(11):e0207261.

65. Inwood E, Ferrari M. Mechanisms of change in the relationship between selfcompassion, emotion regulation, and mental health: a systematic review. Appl Psychol Health Well Being. 2018;10(2):215-235.

66. Gratz KL, Roemer L. Multidimensional assessment of emotion regulation and dysregulation: development, factor structure, and initial validation of the difficulties in emotion regulation scale. J Psychopathol Behav Assess. 2004;26(1):41-54.

67. Berking M, Whitley B. Affect regulation training: A practitioner's manual. New York: Springer Science + Business Media; 2014 . 
68. Aldao A, Nolen-Hoeksema S, Schweizer S. Emotion-regulation strategies across psychopathology: a meta-analytic review. Clin Psychol Rev. 2010;30(2):217-237.

69. Allen AB, Leary MR. Self-Compassion, stress, and coping. Soc Personal Psychol Compass. 2010;4(2):107-118.

70. Finlay-Jones AL, Rees CS, Kane RT. Self-compassion, emotion regulation and stress among Australian psychologists: testing an emotion regulation model of self-compassion using structural equation modeling. PLoS One. 2015;10(7):e0133481.

71. Kirschner H, Kuyken W, Wright K, Roberts H, Brejcha C, Karl A. Soothing your heart and feeling connected: a new experimental paradigm to study the benefits of selfcompassion. Clin Psychol Sci. 2019;7(3):545-565.

72. Bellosta-Batalla M, Ruiz-Robledillo N, Sariñana-González P, Capella-Solano T, VitoriaEstruch S, Hidalgo-Moreno G, et al. Increased salivary IgA response as an indicator of immunocompetence after a mindfulness and self-compassion-based intervention. Mindfulness. 2018;9(3):905-913.

73. Lloyd J, Muers J, Patterson TG, Marczak M. Self-compassion, coping strategies, and caregiver burden in caregivers of people with dementia. Clin Gerontol. 2019;42(1):47-59.

74. Hlabangana V, Hearn JH. Depression in partner caregivers of people with neurological conditions; associations with self-compassion and quality of life. J Ment Health. 2019:16.

75. Collins RN, Gilligan LJ, Poz R. The evaluation of a compassion-focused therapy group for couples experiencing a dementia diagnosis. Clin Gerontol. 2018;41(5):474-486. 
76. Gilbert P, McEwan K, Matos M, Rivis A. Fears of compassion: development of three self-report measures. Psychol Psychother. 2011;84(3):239-255.

77. Germer C. The mindful path to self-compassion: Freeing yourself from destructive thoughts and emotions. New York: Guilford Press; 2009.

78. Gonyea JG, Paris R, de Saxe Zerden L. Adult daughters and aging mothers: the role of guilt in the experience of caregiver burden. Aging Ment Health. 2008;12(5):559-567.

79. Kirby JN, Tellegen CL, Steindl SR. A meta-analysis of compassion-based interventions: current state of knowledge and future directions. Behav Ther. 2017;48(6):778-792.

80. Yardley L, Ainsworth B, Arden-Close E, Muller I. The person-based approach to enhancing the acceptability and feasibility of interventions. Pilot Feasibility Stud. 2015;1:37.

81. Price A, Albarqouni L, Kirkpatrick J, Clarke M, Liew SM, Roberts N, et al. Patient and public involvement in the design of clinical trials: an overview of systematic reviews. $J$ Eval Clin Pract. 2018;24(1):240-253. 